\title{
Direct Laser Processing of Two-Scale Periodic Structures for Superhydrophobic Surfaces Using a Nanosecond Pulsed Laser
}

\author{
Hidenori Shimada ${ }^{1}$ D Shunichi Kato ${ }^{1} \cdot$ Takumi Watanabe $^{1} \cdot$ \\ Masaki Yamaguchi ${ }^{1}$
}

Accepted: 20 October 2020/Published online: 29 October 2020

(C) The Author(s) 2020

\begin{abstract}
Hierarchical structures are promising geometries for superhydrophobic surfaces, however a processing method with a single laser light source that is capable of both onepass and rapid processing has not been established. The purpose of this study was to propose a concept of direct laser processing of two-scale periodic structures exhibiting superhydrophobicity. We hypothesized that the molten material that occurs due to the expanding plasma and that is squeezed around the micro-holes could play an active role in the processing of two-scale periodic structures. Percussion drilling using a nanosecond pulsed laser (532 nm wavelength) was performed on a steel surface. Twenty four different test-pieces were prepared using pitch $(16-120 \mu \mathrm{m})$, number of repetition shots (1-120), and fluence $\left(2.49-20 \mathrm{~J} / \mathrm{cm}^{2}\right)$, as the parameters. As the results, micro-holes with bank-shaped outer rims were formed. The maximum apparent contact angle was $161.4^{\circ}$ and the contact angle hysteresis was $4.2^{\circ}$ for a pitch of $80 \mu \mathrm{m}$ and 20 repetition shots. The calculated results for the apparent contact angles were consistent with the measured results. Finally, an equation for estimating the processing rate was proposed. We demonstrated that this direct processing method can achieve a maximum processing rate of $823 \mathrm{~mm}^{2} / \mathrm{min}$.
\end{abstract}

Keywords Direct laser processing · Hydrophobicity · Two-scale periodic structure · Nanosecond pulsed laser $\cdot$ Steel

Masaki Yamaguchi

masakiy@shinshu-u.ac.jp

1 Graduate School of Medicine, Science \& Technology, Shinshu University, 3-15-1 Tokida, Ueda, Nagano 386-8567, Japan 


\section{Introduction}

Nature-inspired surface engineering has flourished over the past two decades. Novel biomimetic surfaces similar to those found in nature have been developed to realize improved physical properties of wettability for applications such as liquid repellency, low adhesion, self-cleaning, and drag reduction [1-5]. A surface structure that has two different-scales and exhibits such physical functions is known as a functional texture. A surface is categorized as being hydrophobic if its apparent contact angle, $\theta^{\prime}$, of water is greater than $90^{\circ}[6]$ and superhydrophobic if $\theta^{\prime}$ of water is greater than $>150^{\circ}$ and the contact angle hysteresis, $C A H$, of water is less than $10^{\circ}$ [7] or $5^{\circ}$ [8]. Superhydrophobic surfaces can be produced by mimicking lotus leaves, which possess hierarchical structures with two-scales [9]. Several fabrication methods based on lithographic techniques have been proposed for producing two-scale periodic structures $[4,10$, 11]. However, a fabrication method that can process two-scale periodic structures simultaneously, one-pass possessing, is yet to be established using a lithographybased approach.

In terms of drilling micro-holes, lasers have shown excellent performance, and commonly used drilling techniques are percussion drilling [12], trepanning [13], and laser helical drilling [14]. Pulsed laser sources such as nanosecond [15], picosecond [16], and femtosecond pulsed lasers [17] can be used to create various structures in an open environment and in an acceptable time. Interference patterning has been proposed for fabricating two-scale periodic structures simultaneously on industrial materials such as metals and resins. However, laser-induced periodic structures, LIPSS, are sometimes limited regarding small-scale structures with no periodicity $[18,19]$. Also, direct laser interface patterning, DLIP, with two or more laser beams [20, 21] is limited for structures, especially given that the pitch cannot be set arbitrarily. Therefore, onepass processing to create any periodic structures with a single laser light source is needed. This is a barrier to fast laboratory-to-fabrication transfer of two-scale periodic structures, especially in the industrial field of processing.

The main feature of femtosecond pulsed lasers is a clear ablation threshold. Compared with nanosecond pulsed lasers, femtosecond pulsed lasers minimize the thermal damage [22]. In contrast, a micro-hole formed by a nanosecond pulsed laser is surrounded by an outer rim comprising molten material squeezed out of the hole by the expanding plasma [23]. The processing of materials by means of short pulsed lasers has evolved significantly and is starting to show its industrial potential for creating regions smaller than $1 \mu \mathrm{m}$ in size $[19,24]$. The possibility of introducing micro-patterns directly using short pulsed lasers has been demonstrated on the surfaces of metals [25] and resins [26]. Realizing direct laser processing would improve the wetting properties that can be achieved with one-pass processing [27, 28]. An optical method using a cylindrical lens has been proposed [29], however the inertial mass of the component parts limits the extent to which the processing rate can be improved. For functional textures, a strategy is required for processing two-scale periodic structures satisfying both one-pass and rapid processing.

We hypothesized that the molten material that is squeezed out of the micro-holes could play an active role in processing two-scale periodic structures. This nanosecond pulsed laser processing is dominated by the melt-pool dynamics due to Marangoni stress, which lead to the formation of bank-shaped outer rims [30]. The purpose of this 
study was to propose a concept that enables both one-pass and rapid laser processing of two-scale periodic structures simultaneously with arbitrarily pitch on the surface of a material by percussion drilling using a nanosecond pulsed laser. To explore this, we performed percussion drilling to fabricate two-scale periodic structures on test-pieces of steel. The wetting behavior in the form of contact angles and contact angle hysteresis were measured after annealing. The optimum conditions for direct processing leading to superhydrophobicity were shown both experimentally and theoretically. To reveal the processing efficiency, the area processed per unit time, i.e. processing rate, of the two-scale periodic structures processed using a nanosecond pulsed laser was estimated.

\section{Materials and Methods}

\section{Direct Laser Processing}

A steel (PSL, Ra $=0.26$ ( $n=24)$ of surface roughness, 33-37 HRC of hardness, Hitachi Metals Tool Steel Ltd., Tokyo, Japan) was used as the material fabricating a squareshaped test-piece (test-piece for wettability evaluation, $20 \mathrm{~mm}$ length $\times 20 \mathrm{~mm}$ width $\times$ $5 \mathrm{~mm}$ thickness) to produce two-scale periodic structures on the surfaces. Because of the difficulty of cutting a thin rod, a pin-shaped steel (SKD-11, 58.0 HRC of hardness, Hitachi Metals Tool Steel, Ltd.) was instead used for a pin-shaped test-piece (test-piece for depth evaluation, $1.5 \mathrm{~mm}$ diameter) to estimate the depth of the percussion drilling. Table 1 shows element compositions of steels used for fabricating test-pieces.

The processing of a two-scale periodic structure using a nanosecond pulsed laser is shown schematically in Fig. 1. The two-scale periodic structure consist from (i) a basically periodic surface structure formed by the pitch of the percussion drilling and (ii) a small-scale periodic surface structure formed by the molten material around the micro-holes. A commercial nanosecond pulsed laser system (ML-9011A, $10 \mathrm{~W}, \mathrm{YVO}_{4}$ solid-state laser, Amada Miyachi Co., Ltd., Isehara, Japan) that provides an oscillation wavelength of $532 \mathrm{~nm}$, a pulse width of $11 \mathrm{~ns}$, and a repetition rate of $20 \mathrm{kHz}$ was used for the experiment (Fig. 1a). The laser beam with a Gaussian profile was focused perpendicularly on the test-piece using a beam expander $(\times 8$, Geomatec Co. Ltd., Kanagawa, Japan), using an $\mathrm{f} \theta$ lens (focal length: $f=160 \mathrm{~mm}$, Geomatec Co. Ltd., Kanagawa, Japan) and two-dimensional galvanometric mirrors. The spot diameter at the focal point on the test-piece surface was calculated as $16 \mu \mathrm{m}$ by $1 / \mathrm{e}^{2}$ using a laser beam quality factor of $M^{2}=1.2$ and an expanded laser beam diameter of $8 \mathrm{~mm}$ [31].

The laser scanning route consisted of parallel beam lines, the distance (pitch) between which was used as a parameter, $\tau\left(\tau_{x}=\tau_{y}\right.$, Fig. 1b). The laser scanning velocity, $\mathrm{v}_{\mathrm{s}}$, was set to $1500 \mathrm{~mm} / \mathrm{s}$ for both directions, achieved using the two-

Table 1 Element compositions of steels used for fabricating test-pieces

\begin{tabular}{lllllllllll}
\hline Test-piece & Model number & $\mathrm{Fe}$ & $\mathrm{C}$ & $\mathrm{Si}$ & $\mathrm{Mn}$ & $\mathrm{Ni}$ & $\mathrm{Cr}$ & $\mathrm{Mo}$ & $\mathrm{V}$ & $\mathrm{Cu}$ \\
\hline Wettability evaluation & PSL & 75.06 & 0.04 & 0.4 & 0.8 & 4.5 & 15.5 & 0.7 & 0 & 3.0 \\
Depth evaluation & SKD-11 & 84.60 & 1.5 & 0.3 & 0.4 & 0 & 12.0 & 0.9 & 0.3 & 0 \\
\hline
\end{tabular}


(a) Nanosecond pulsed laser processing system

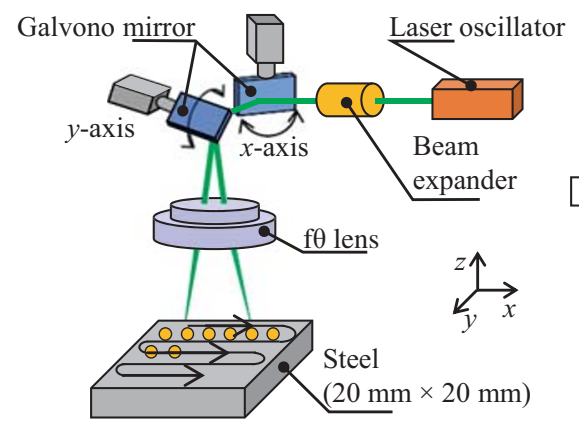

(d) Two-scale periodic structures

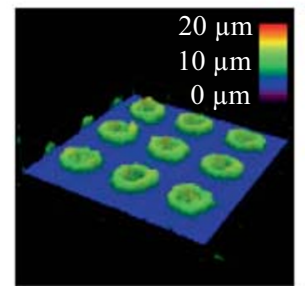

(An image of 3-dimensional view) (b) Processing pattern of percussion drilling

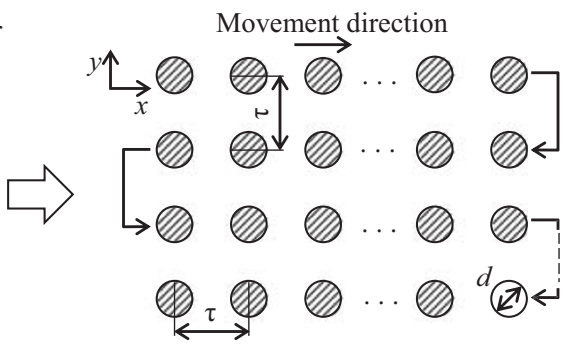

$\tau$ : pitch, $d$ : laser spot diameter<smiles>C1CC2CCCC2C1</smiles>

(c) Processing of percussion drilling

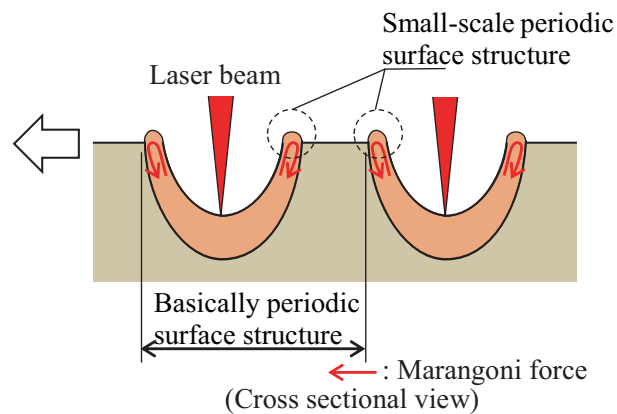

Fig. 1 Machining process of two-scale periodic structures on a metal surface by percussion drilling using a nanosecond pulsed laser

dimensional galvanometric mirrors. The nanosecond pulsed laser was used for percussion drilling so that both thermal and ablation processes would occur (Fig. 1c). Consequently, a two-scale periodic structure is formed by processing two periodic structures simultaneously (Fig. 1d).

Twenty four test-pieces for wettability evaluation were prepared using the pitch (16$120 \mu \mathrm{m})$, number of repetition shots, $s(1-120)$, and fluence, $F\left(2.49-20 \mathrm{~J} / \mathrm{cm}^{2}\right)$, as the parameters (Table 2).

\section{Measurement of Two-Scale Periodic Structure}

The various surface geometries of the test-pieces for wettability evaluation were compared using experimental observations made perpendicularly with a non-contact laser confocal microscope ( $1 \mathrm{~nm}$ resolution for depth, OLS4100, Olympus Co., Tokyo, Japan) for all the test-piece for wettability evaluation. However, it was difficult to use the laser confocal microscope to measure the depth of the percussion drilling because of the high $(>1)$ aspect ratio (depth-to-diameter ratio) of the holes. Instead, we used a highresolution three-dimensional X-ray microscopy (micro-CT, $2 \mu \mathrm{m}$ resolution, SKYSCAN 1272, Bruker Japan K.K., Tokyo, Japan) to measure the depth nondestructively in the test-pieces for depth evaluation. Metal suffers from low X-ray 
Table 2 Fabricated test-pieces for wettability evaluation used for direct laser processing of two-scale periodic structures

\begin{tabular}{|c|c|c|c|c|c|}
\hline Sample no. & Pitch $\tau(\mu \mathrm{m})$ & $\begin{array}{l}\text { Number of repetition } \\
\text { shots } s\end{array}$ & $\begin{array}{l}\text { Fluence } F \\
\left(\mathrm{~J} / \mathrm{cm}^{2}\right)\end{array}$ & $\begin{array}{l}\text { Pulse width } t \\
\text { (ns) }\end{array}$ & $\begin{array}{l}\text { Spot diameter } d \\
(\mu \mathrm{m})\end{array}$ \\
\hline 1 & 16 & 1 & 20.0 & 11 & 16 \\
\hline 2 & & 20 & & & \\
\hline 3 & & 40 & & & \\
\hline 4 & & 80 & & & \\
\hline 5 & & 120 & & & \\
\hline 6 & 40 & 1 & & & \\
\hline 7 & & 20 & & & \\
\hline 8 & & 40 & & & \\
\hline 9 & & 80 & & & \\
\hline 10 & & 120 & & & \\
\hline 11 & 80 & 1 & & & \\
\hline 12 & & 20 & & & \\
\hline 13 & & 40 & & & \\
\hline 14 & & 80 & & & \\
\hline 15 & & 120 & & & \\
\hline 16 & 120 & 1 & & & \\
\hline 17 & & 20 & & & \\
\hline 18 & & 40 & & & \\
\hline 19 & & 80 & & & \\
\hline 20 & & 120 & & & \\
\hline 21 & 40 & 80 & 2.49 & & \\
\hline 22 & & & 4.98 & & \\
\hline 23 & & & 7.46 & & \\
\hline 24 & & & 9.95 & & \\
\hline
\end{tabular}

transmittance, therefore we used thin test-pieces for depth evaluation (1.5 mm diameter) for cross-sectional observation under the same processing conditions as those used for the test-pieces for wettability evaluation. The measurements were repeated for five times $(n=5)$, and the mean values were used.

\section{Apparent Contact Angle and Contact Angle Hysteresis}

The equilibrium contact angle, $\theta$, apparent contact angle, $\theta^{\prime}$, and contact angle hysteresis $\left(C A H=\theta_{\text {rec }}-\theta_{\text {adv }}\right)$ of the test-pieces for wettability evaluation were measured using a commercial contact angle analyzer (DM-701, Kyowa Interface Science Co. Ltd., Niiza, Japan) by dropping a droplet of distilled water from a microsyringe. The volume of droplet was $2 \mu \mathrm{L}$ for measuring $\theta$ and $\theta$ '. The volume of droplet was $30 \mu \mathrm{L}$ for measuring $C A H$. The measurements of $\theta$ and $\theta$ ' were repeated for five times $(n=5)$, and the mean values were used. For $C A H$, time-course changes of $C A H$ s were measured, and the mean values of five data points $(n=5)$ were used. 
It has been reported that wetting behavior is related to the amount of organic compounds on the surface with time [32-34]. Therefore, the time-course changes of the apparent contact angles were measured for a month and a half period to capture any changes. Immediately after the laser processing, the test-pieces were kept at $48^{\circ} \mathrm{C}$ in an incubator (MIR-153, PHC Holdings Co., Tokyo, Japan) during this evaluation to accelerate the oxidation aging.

\section{Estimation of Processing Rate}

Figure 2 shows a time chart of the nanosecond pulsed laser used for this laser processing. The processing time per shot, $t$, is shown by the sum of (i) the percussion drilling time, $t_{\mathrm{p}}$, (ii) the time taken to move the scanner to the next position, $t_{\mathrm{m}}$, and (iii) the scanner settling time, $t_{s}$. as follows:

$$
t=t_{\mathrm{p}}+t_{\mathrm{m}}+t_{s}(\mathrm{~s})
$$

The percussion drilling time, $t_{\mathrm{p}}$, is given as follows:

$$
t_{\mathrm{p}}=\frac{s}{f}=\frac{s}{20} \times 10^{-3}
$$

where, $s$ : Number of irradiations $(=1-120)$,

$f$ : repetition rate, $=20 \mathrm{kHz}$.

\section{(a) Moving of scanner}

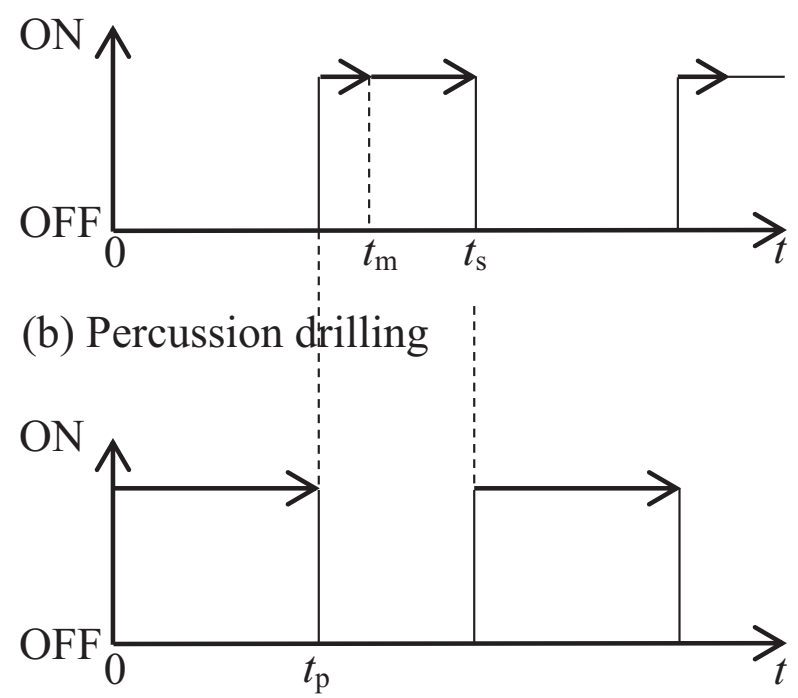

Fig. 2 Time chart of nanosecond pulsed laser $\left(t_{\mathrm{m}}\right.$ : moving time of scanner, $t_{s}$ : settling time of scanner, $t_{\mathrm{p}}$ : percussion drilling time) 
In this experiment, $t_{\mathrm{p}}$ was between 0.05 and $6 \mathrm{~ms}$. The maximum value of $t_{\mathrm{m}}\left(=\tau / \mathrm{v}_{\mathrm{s}}\right)$ was estimated as $0.08 \mathrm{~ms}$ from the laser scanning velocity $\left(\mathrm{v}_{\mathrm{S}}=1500 \mathrm{~mm} / \mathrm{s}\right)$ and the maximum pitch $(\tau=120 \mu \mathrm{m})$. For the present nanosecond pulsed laser system, $t_{s}$ was $1 \mathrm{~ms}$, in which case $t_{\mathrm{m}}$ is negligible. Thus, the total processing time, $T$, is expressed in terms of the number of holes, $N$, as follows:

$$
T=\left(\frac{s}{f}+1\right) \times N \times 10^{-3}
$$

When both the pitch $\left(\tau_{x}=\tau_{y}\right)$ and the length of the processed area $\left(l_{x}=l_{y}=l\right)$ are the same in both directions, the number of holes per unit area, $N$, is given as follows:

$$
N=\frac{l_{x}}{\tau} \times \frac{l_{y}}{\tau}=\left(\frac{l}{\tau}\right)^{2}=\frac{1}{\tau^{2}}\left(1 / \mathrm{m}^{2}\right)
$$

Thus, the processing rate, $v$, is given as follows:

$$
v=\frac{1}{T}=\frac{\tau^{2} \times 10^{3}}{\frac{s}{f}+1}\left(\mathrm{~m}^{2} / \mathrm{s}\right)=\frac{6 \times 10^{10} \times \tau^{2}}{\frac{s}{f}+1}\left(\mathrm{~mm}^{2} / \mathrm{min}\right)
$$

\section{Results and Discussion}

\section{Measurement of Periodic Structure}

Figure 3 shows a sequence of laser confocal microscope micrographs of the test-pieces for wettability evaluation for various laser fluences (samples no. 21-24 in Table 2). As expected, crater-shaped holes were observed in the direction of the laser beam. It was considered that the bank-shaped outer rim around each micro-hole was formed by the molten material which was squeezed out of the micro-hole by the expanding plasma. Mirza et al. reported that craters could be processed by using a femtosecond pulsed laser, however the heights of the outer rim did not change significantly [23]. In Fig. 4, the structure processed on steel by percussion drilling is illustrated schematically as a two-scale periodic structure, where $f_{1}$ is the width of the solid-liquid interface, $f_{2}$ is the width of the liquid-air interface, $h_{1}$ is the depth of the basically periodic surface structure, $f_{\mathrm{s} 1}$ is the width of the small-scale periodic surface structure, and $h_{2}$ is the bank height of the small-scale periodic surface structure. The values of $f_{\mathrm{s} 1}$ could not be determined under the condition of $16 \mu \mathrm{m}$ pitch due to the overlap of two-scale periodic structures. The value of $f_{\mathrm{s} 1}$ was in the range of 2.9-10.2 $\mu \mathrm{m}$. The values of the bank height, $h_{2}$, for fluence values of $2.94,4.98,7.46$, and $9.95 \mathrm{~J} / \mathrm{cm}^{2}$ were $0.7,2.8,6.0$, and $8.2 \mu \mathrm{m}$, respectively. Therefore, we reason that the bank-shaped outer rim was caused by the molten material generated by the expanding plasma of the nanosecond pulsed 

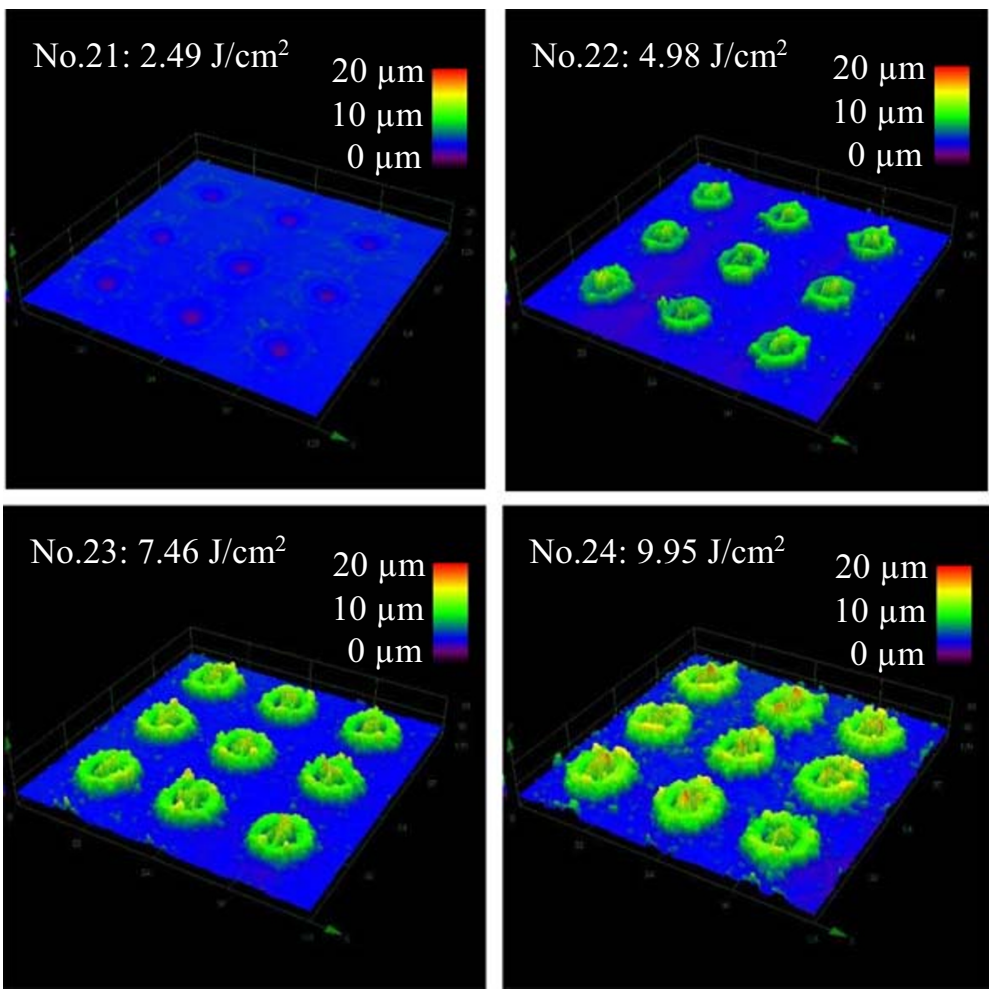

Fig. 3 Three-dimensional images of surface morphology for fluences of $2.49 \mathrm{~J} / \mathrm{cm}^{2}$ (no. 21 ), $4.98 \mathrm{~J} / \mathrm{cm}^{2}$ (no. 22), $7.46 \mathrm{~J} / \mathrm{cm}^{2}$ (no. 23), and $9.95 \mathrm{~J} / \mathrm{cm}^{2}$ (no. 24)

laser, meaning that the bank height could be controlled when using a nanosecond pulsed laser.

The results for the geometrical parameters of the two-scale periodic structures measured using the non-contact laser confocal microscope are shown in Table 3 . The value of $h_{1}$ at $\tau=16 \mu \mathrm{m}$ could not be measured because adjacent processing areas interfered. For sufficient pitch length, $h_{1}$ was considered to be almost constant and

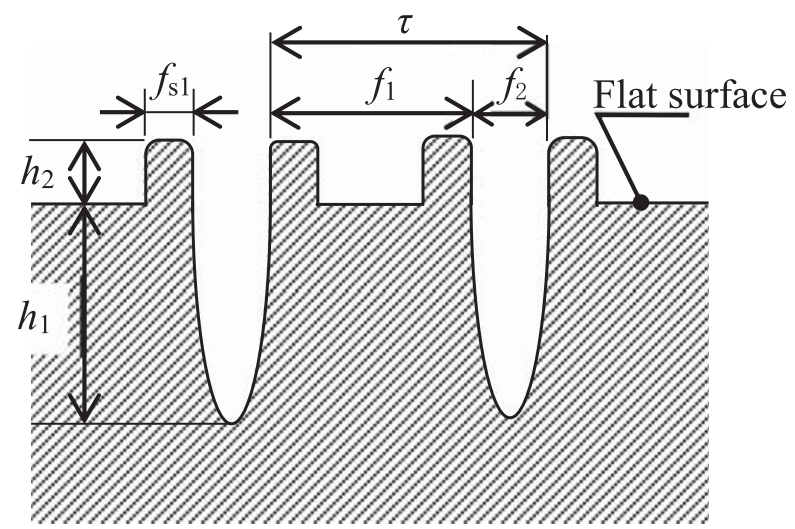

Fig. 4 Schematic depiction of laser processed two-scale periodic structures on steel by percussion drilling 
Table 3 Measured results for the two-scale periodic structures and the contact angles $\left(F=20 \mathrm{~J} / \mathrm{cm}^{2}\right)$

\begin{tabular}{|c|c|c|c|c|c|c|c|c|c|c|c|}
\hline \multirow{2}{*}{$\begin{array}{l}\text { Pitch } \tau \\
(\mu \mathrm{m})\end{array}$} & \multirow{2}{*}{$\begin{array}{l}\text { Number of repetition } \\
\text { shots, } s\end{array}$} & \multicolumn{10}{|c|}{ Measured results } \\
\hline & & ${ }_{(\mu \mathrm{m})}^{\tau}$ & $\begin{array}{r}f_{1} \\
(\mu \mathrm{m})\end{array}$ & $\begin{array}{r}f_{2} \\
(\mu \mathrm{m})\end{array}$ & $\begin{array}{l}{ }^{* 1} f s_{1} \\
(\mu \mathrm{m})\end{array}$ & $\begin{array}{l}{ }^{* 2} h_{1} \\
(\mu \mathrm{m})\end{array}$ & $\begin{array}{c}h_{2} \\
(\mu \mathrm{m})\end{array}$ & $f_{1} / \tau$ & $\begin{array}{l}f_{2} / \\
f_{1}\end{array}$ & $\begin{array}{l}* 3 \theta^{\prime} \\
\left({ }^{\circ}\right)\end{array}$ & $\begin{array}{l}C A H \\
\left({ }^{\circ}\right)\end{array}$ \\
\hline \multirow[t]{5}{*}{16} & 1 & 16.1 & 6.3 & 9.8 & - & $* 4$ & 2.3 & 0.39 & 1.56 & 146.0 & 81.9 \\
\hline & 20 & 16.2 & 7.2 & 9.0 & - & - & 12.5 & 0.44 & 1.25 & 148.8 & 24.5 \\
\hline & 40 & 16.1 & 7.3 & 8.8 & - & - & 21.6 & 0.45 & 1.21 & 155.9 & 11.0 \\
\hline & 80 & 16.4 & 8.5 & 7.9 & - & - & 19.0 & 0.52 & 0.93 & 154.1 & 10.5 \\
\hline & 120 & 16.6 & 8.3 & 8.3 & - & - & 17.3 & 0.50 & 1.00 & 153.7 & 20.5 \\
\hline \multirow[t]{5}{*}{40} & 1 & 40.7 & 17.5 & 23.2 & 2.9 & 1.6 & 1.0 & 0.43 & 1.32 & 141.7 & 59.0 \\
\hline & 20 & 40.9 & 21.9 & 18.9 & 6.9 & 30.6 & 10.1 & 0.54 & 0.86 & 157.6 & 12.3 \\
\hline & 40 & 40.3 & 22.8 & 17.5 & 9.4 & - & 11.7 & 0.57 & 0.77 & 158.9 & 17.3 \\
\hline & 80 & 40.5 & 25.4 & 15.1 & 10.1 & - & 12.5 & 0.63 & 0.60 & 158.2 & 9.9 \\
\hline & 120 & 40.4 & 23.6 & 16.7 & 10.0 & - & 11.4 & 0.59 & 0.71 & 157.7 & 7.4 \\
\hline \multirow[t]{5}{*}{80} & 1 & 79.5 & 53.1 & 26.4 & 3.1 & 2.0 & 1.5 & 0.67 & 0.50 & 143.4 & 78.0 \\
\hline & 20 & 79.6 & 59.1 & 20.5 & 6.5 & 30.5 & 8.6 & 0.74 & 0.35 & 161.4 & 4.2 \\
\hline & 40 & 79.7 & 65.9 & 13.8 & 9.3 & - & 13.1 & 0.83 & 0.21 & 160.8 & 14.6 \\
\hline & 80 & 79.3 & 64.4 & 14.9 & 10.0 & - & 13.4 & 0.81 & 0.23 & 160.3 & 18.9 \\
\hline & 120 & 79.9 & 65.1 & 14.9 & 10.2 & - & 11.8 & 0.81 & 0.23 & 158.9 & 20.6 \\
\hline \multirow[t]{5}{*}{120} & 1 & 119.3 & 93.0 & 26.3 & 3.6 & 1.9 & 1.4 & 0.78 & 0.28 & 134.8 & 52.6 \\
\hline & 20 & 121.2 & 101.2 & 20.1 & 6.2 & 32.2 & 10.0 & 0.83 & 0.20 & 139.7 & 75.4 \\
\hline & 40 & 120.5 & 103.9 & 16.6 & 9.3 & - & 11.9 & 0.86 & 0.16 & 140.6 & 87.5 \\
\hline & 80 & 121.2 & 103.8 & 17.3 & 10.0 & - & 11.9 & 0.86 & 0.17 & 141.9 & 91.1 \\
\hline & 120 & 120.9 & 103.6 & 17.4 & 9.9 & - & 13.1 & 0.86 & 0.17 & 141.7 & 98.7 \\
\hline
\end{tabular}

*1: Width of the small-scale periodic structure, $f_{s_{1}}$, could not be determined due to the overlap of the two-scale periodic structures

*2: Depth of hole, $h_{1}$, could not be measured by the laser confocal microscope because the aspect ratio

*3: Equilibrium contact angle was $\theta=97.3^{\circ} \pm 3.2^{\circ}$ (mean $\pm \mathrm{SD}$ )

*4: - shows the data which cannot be measured. $n=5$

independent of the pitch. The $f_{1} / \tau$ ratio was in the range of $0.37-0.87$, increasing in proportion to the pitch. Thus, the $f_{2} / f_{1}$ ratio was in the range of $0.15-1.69$, decreasing in proportion to the pitch. The diameter, $f_{2}$, changed with the pitch distance and the number of laser pulses. It was considered that the molten material was squeezed around the micro-holes in proportion to the number of laser pulses, whereupon $f_{2}$ decreased.

Figure 5 shows the results for the hole depth, $h_{1}$, measured using the test-pieces for depth evaluation and three-dimensional X-ray microscopy because the aspect ratio of the holes prevented them from being measured fully using the laser confocal microscope. Figure 5a and $\mathrm{b}$ show how $h_{1}$ varied with the fluence, $F$, and the number of repetition shots, $s$, respectively. The value of $h_{1}$ increased linearly in proportion to the fluence (Fig. 5a). The absolute values of $h_{1}$ for the SKD-11 steel were similar to those of the PSL steel for $s=1$ and 20 (Table 3). The compositional differences between the two steels were those regarding $\mathrm{C}, \mathrm{Ni}, \mathrm{V}$, and $\mathrm{Cu}$, clarified as being a few percent. 


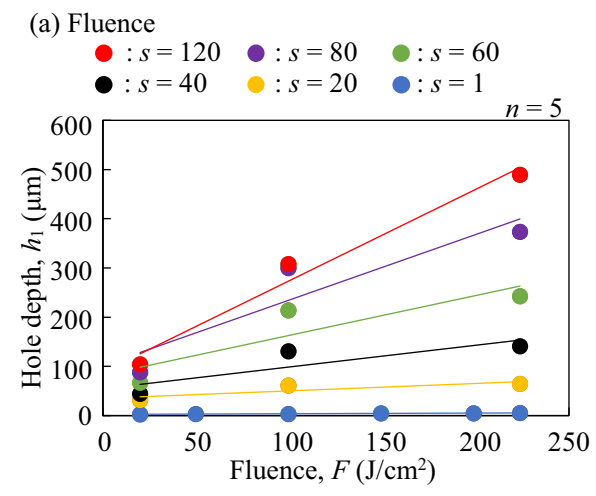

(b) Number of repetition shot

: $224 \mathrm{~J} / \mathrm{cm}^{2} \Delta: 100 \mathrm{~J} / \mathrm{cm}^{2} \square: 20 \mathrm{~J} / \mathrm{cm}^{2}$

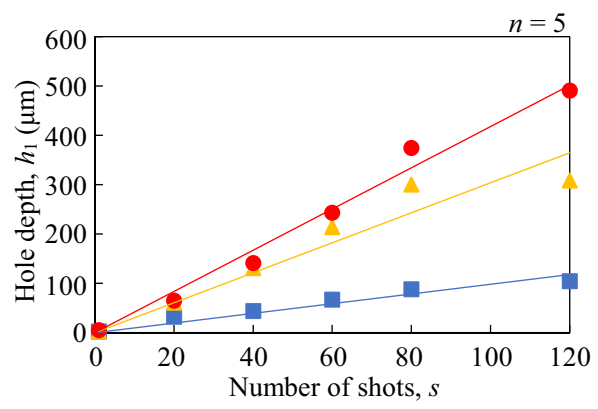

Fig. 5 Variation of hole depth, $h_{1}$, with fluence, $F$, and number of repetition shots, $s$

Thus, it was considered that the ablation thresholds of the two used steels comparable to lead to the same surface features. A limitation was that the single pulse results should be excluded because of the resolution of the micro-CT. The hole depth could potentially increase exponentially because reflectivity decreases with increasing temperature [35]. However, the value of $h_{1}$ also increased linearly in proportion to the number of repetition shots (Fig. 5b). Therefore, we assumed our conditions limited the increase in surface temperature sufficiently so that we can use both the fluence and the number of repetition shots to estimate the hole depth in a linear manner. These data were used to estimate the processing rate for the two-scale periodic structures.

\section{Apparent Contact Angle and Contact Angle Hysteresis}

Figure 6 shows the time-course changes of the apparent contact angles immediately after the laser processing of the test-pieces for wettability evaluation (samples no. 1-20 in Table 2). The apparent contact angles of the steel surfaces increased over time, and the surfaces became nearly superhydrophobic. Jagdheesh et al. reported that laser processing of metal surfaces creates preferential sites for the adsorption of organic compounds from the air [26]. The change in wetting behavior was correlated with the amount of carbon on the structured surfaces [33]. It was considered that the apparent contact angles to have stabilized after 4 weeks and we used those values to evaluate the hydrophobicity.

The maximum contact angles after aging for each test-piece for wettability evaluation are shown in Table 3. The measured apparent contact angle increased as the pitch increases from 16 to $80 \mu \mathrm{m}$, after which it decreased. The maximum apparent contact angle of $161.4^{\circ}$ was associated with a pitch of $80 \mu \mathrm{m}$ and 20 repetition shots. This condition might be the optimum condition based on the Cassie-Baxter equation. This superhydrophobicity was equal to or above with the previous report of the hierarchical structure [36]. Also, the same conditions are associated with the minimum contact angle hysteresis of $4.2^{\circ}$. These results agreed well with those in a previous report that found the hysteresis values to be less than $10^{\circ}$ when the apparent contact angle exceeded $150^{\circ}$ [37].

It seems that the contact angle did not change much after a few pulses (Table 3 ). In particular, the contact angle for $\mathrm{s} \geq 20$ remained almost constant for pitch values of 40 
a : $40 \mu \mathrm{m}$

$0: 1$

$\triangle: 20$

$\square: 40 \diamond: 80 \quad \nabla: 120$

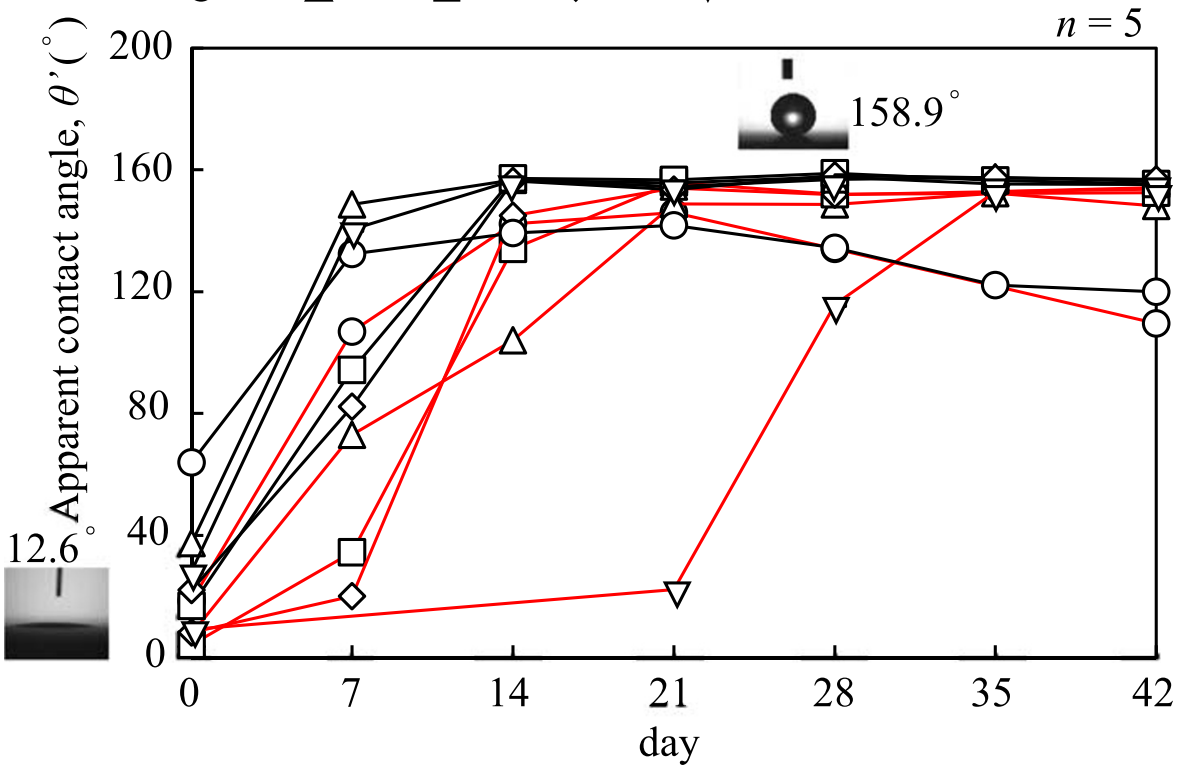

b $\quad-: 80 \mu \mathrm{m} \_: 120 \mu \mathrm{m}$
$0: 1 \quad \Delta: 20$
$\square: 40 \diamond: 80 \quad \nabla: 120$

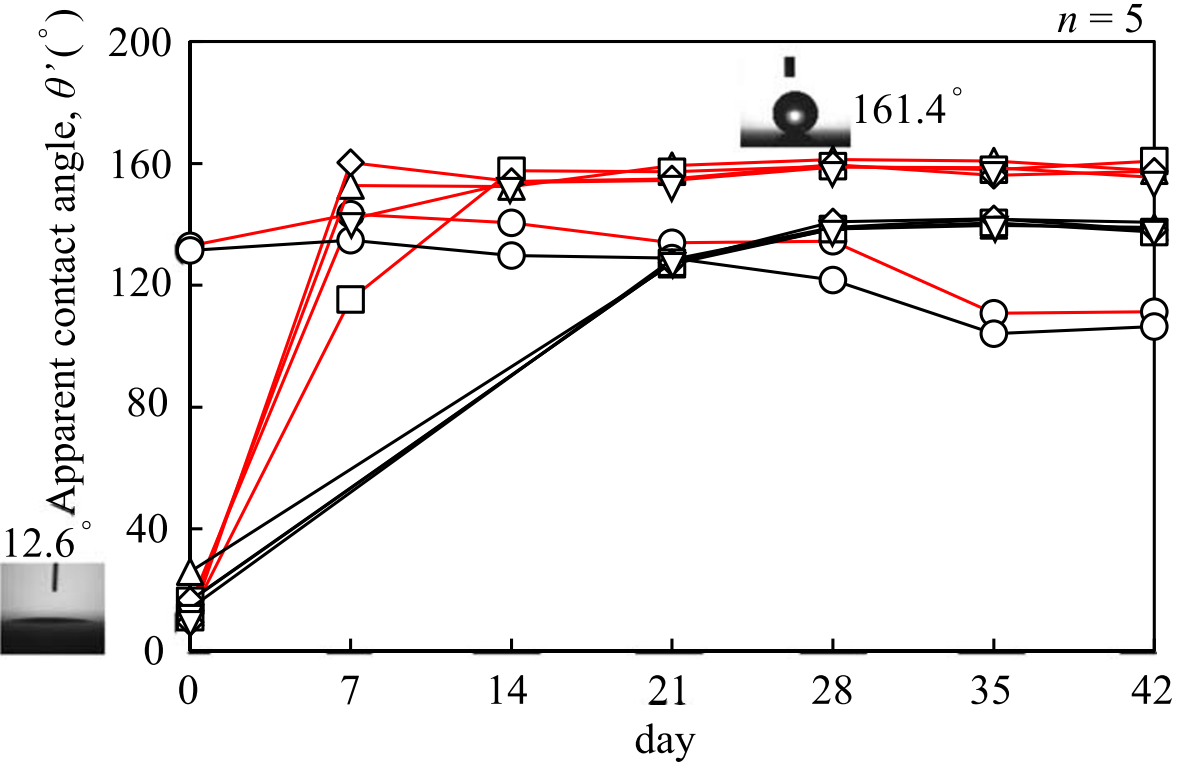

Fig. 6 Time-course changes of apparent contact angles 
and $80 \mu \mathrm{m}$. These findings suggested that we could focus on using low pulse numbers. Reducing pulse numbers contribute to reduce processing time and heat affected zone. If the number of repetition shots increases, unstable morphology may appear in the pores, which may not be conducive to obtaining a stable superhydrophobic structure.

Table 4 shows the relationship between geometrical parameters and wettability of the two-scale periodic structures. In this table, the depth of the basically periodic surface structure, $h_{1}$, was estimated by using the linear regression analysis between the hole depth and the fluence (Fig. 5a). The $h_{1}$ saturated when fluence exceeded $80 \mathrm{~J} /$ $\mathrm{cm}^{2}$. It was considered that the increase in the hole depth slowed down by the plasma shielding effect [38]. The apparent contact angle showed hydrophobicity when the basically periodic surface structure, $h_{1}$, and the bank height, $h_{2}$, exceeded a threshold level. The absolute values of each threshold level will be changed by geometrical parameters such as pitch.

The values of the apparent contact angle, $\theta$ ', were calculated based on the CassieBaxter equation and introducing a non-dimensional roughness factor $R_{\mathrm{f}}(\geq 1)$ on surface $f_{1}$ as follows $[39,40]$ :

Table 4 Relationship between geometrical parameters and wettability of the two-scale periodic structures

\begin{tabular}{|c|c|c|c|c|c|}
\hline \multirow[t]{2}{*}{$\operatorname{Pitch} \tau(\mu \mathrm{m})$} & \multirow[t]{2}{*}{ Number of repetition shots, $s$} & \multicolumn{4}{|c|}{ Measured results } \\
\hline & & $h_{1} *(\mu \mathrm{m})$ & $h_{2}(\mu \mathrm{m})$ & $f_{1} / \tau$ & $\theta^{\prime}\left({ }^{\circ}\right)$ \\
\hline \multirow[t]{5}{*}{16} & 1 & 2.7 & 2.3 & 0.39 & 146.0 \\
\hline & 20 & 38.5 & 12.5 & 0.44 & 148.8 \\
\hline & 40 & 63.7 & 21.6 & 0.45 & 155.9 \\
\hline & 80 & 127.1 & 19.0 & 0.52 & 154.1 \\
\hline & 120 & 125.5 & 17.3 & 0.50 & 153.7 \\
\hline \multirow[t]{5}{*}{40} & 1 & 2.7 & 1.0 & 0.43 & 141.7 \\
\hline & 20 & 38.5 & 10.1 & 0.54 & 157.6 \\
\hline & 40 & 63.7 & 11.7 & 0.57 & 158.9 \\
\hline & 80 & 127.1 & 12.5 & 0.63 & 158.2 \\
\hline & 120 & 125.5 & 11.4 & 0.59 & 157.7 \\
\hline \multirow[t]{5}{*}{80} & 1 & 2.7 & 1.5 & 0.67 & 143.4 \\
\hline & 20 & 38.5 & 8.6 & 0.74 & 161.4 \\
\hline & 40 & 63.7 & 13.1 & 0.83 & 160.8 \\
\hline & 80 & 127.1 & 13.4 & 0.81 & 160.3 \\
\hline & 120 & 125.5 & 11.8 & 0.81 & 158.9 \\
\hline \multirow[t]{5}{*}{120} & 1 & 2.7 & 1.4 & 0.78 & 134.8 \\
\hline & 20 & 38.5 & 10.0 & 0.83 & 139.7 \\
\hline & 40 & 63.7 & 11.9 & 0.86 & 140.6 \\
\hline & 80 & 127.1 & 11.9 & 0.86 & 141.9 \\
\hline & 120 & 125.5 & 13.1 & 0.86 & 141.7 \\
\hline
\end{tabular}

*: Depth of the basically periodic structure, $h_{1}$, was estimated by using the linear regression analysis between the hole depth and the fluence (Fig.5a, $F=20 \mathrm{~J} / \mathrm{cm}^{2}$ ) 


$$
\cos \theta^{\prime}=-1+\frac{f_{1}}{\tau}\left(R_{f} \cos \theta+1\right)
$$

where $\theta$ is the equilibrium contact angle, and is equal to $97.3 \pm 3.2^{\circ}$ (mean \pm standard deviation, the mean value was calculated using 24 test-pieces for wettability evaluation). This theoretical model adapts the hypothesis that the water is under zero hydrostatic pressure. This model approximates the two structures as a basically periodic surface structure and a small scale structure on surface $f_{1}$. Figure 7 shows the relationship between the apparent contact angle and $f_{1} / \tau$ ratio for these structures. The measured apparent contact angle decreased with increasing $f_{1} / \tau$ ratio. The calculated results agreed well with the measured results when $R_{\mathrm{f}}=1-7$ were used. These results confirmed that the present theoretical model pertains to the two-scale periodic structures.

\section{Estimation of Processing Rate}

Figure 8 shows the processing rate of the two-scale periodic structures calculated using Eq. (5). Under the present conditions, the processing rate ranged between 2 and $823 \mathrm{~mm}^{2} / \mathrm{min}$, increasing with the pitch and decreasing with the number of repetition shots. In this method, the number of repetition shots can be reduced by increasing the fluence. Eq. (5) showed that increasing the repetition rate, $f$, was an effective way to increase the processing rate. Consequently, a maximum processing rate of $823 \mathrm{~mm}^{2} /$ min was achieved with $\tau=120 \mu \mathrm{m}$ and $s=1$. This processing rate equivalent to $28.7 \mathrm{~mm}$ square per $\mathrm{min}$ and/or $222 \mathrm{~mm}$ square per hour. In previous research involving percussion drilling using a nanosecond pulsed laser, Cai et al. used an area

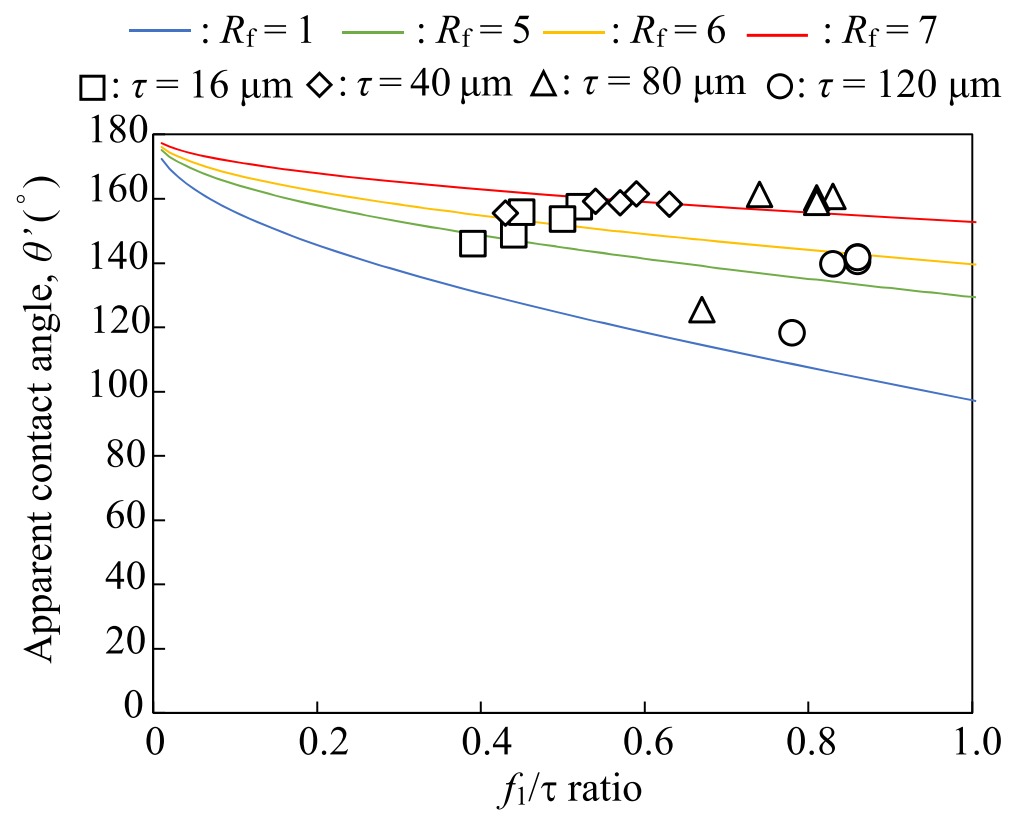

Fig. 7 Relationship between apparent contact angle and $f_{1} / \tau$ ratio of two-scale periodic structures 


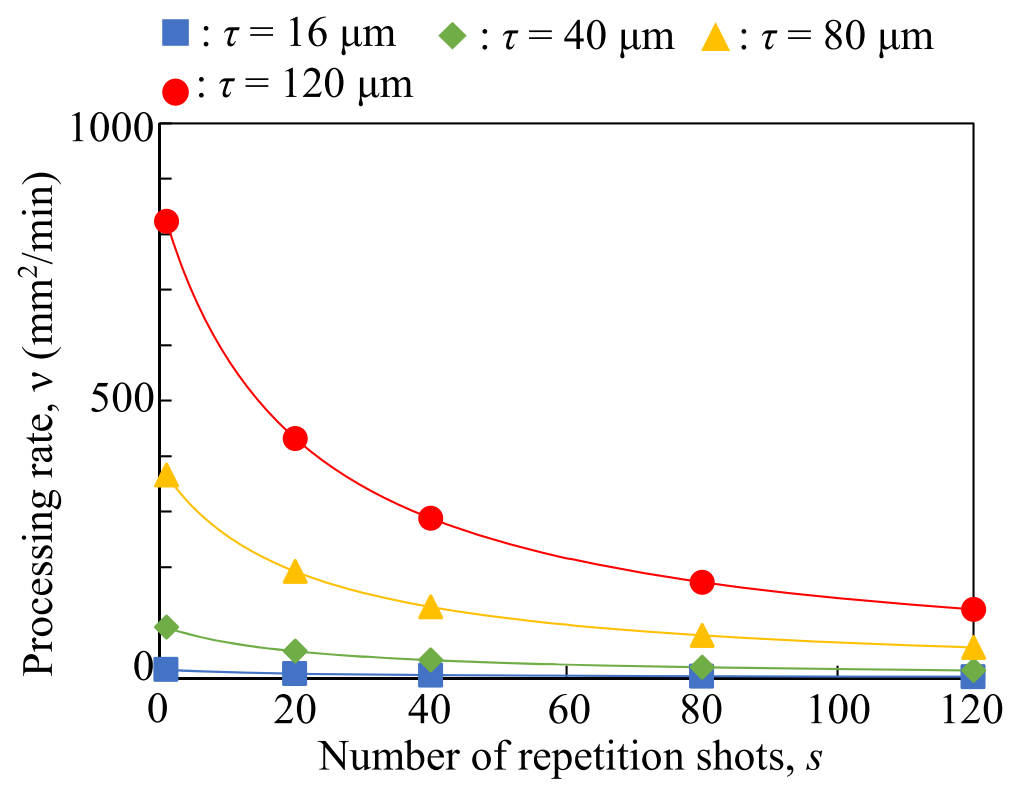

Fig. 8 Estimated processing rate of two-scale periodic structures using nanosecond pulsed laser

of $10 \mathrm{~mm}$ square area, $110.9 \mu \mathrm{m}$ pitch, 1 shot/hole, and $0.4 \mathrm{~s}$ duration time on stainless steel [41]. Yang et al. used a condition of $20 \mathrm{~mm}$ diameter area, $100 \mu \mathrm{m}$ pitch, 24 shots/ hole, and $50 \mathrm{~mm} / \mathrm{s}$ scanning speed on nickel-chromium-based superalloy [42]. Although neither report states the processing rate clearly, we estimated that it was in the range of $1-100 \mathrm{~mm}^{2} / \mathrm{min}$. Therefore, the present results supported the assertion that a rapid fabrication method has been obtained, leading to fast laboratory-to-fabrication transfer. With superhydrophobicity, we can use $s \geq 20$, in which case the processing rate will be $432 \mathrm{~mm}^{2} / \mathrm{min}$ with $\tau=120 \mu \mathrm{m}$. A stop-and-go action is necessary to increase the roundness of the work marks on the workpiece. However, if such stop-andgo action can be avoided and the pulsed laser source moved continuously, then the throughput can be increased substantially.

\section{Conclusion}

We have purposed a concept for the one-pass and rapid laser processing of two-scale periodic structures with arbitrarily set pitch, lead to superhydrophobicity on steel by percussion drilling using a nanosecond pulsed laser with a single laser light source. The molten material due to the expanding plasma squeezed around the micro-holes could play an active role in processing two-scale periodic structures. A maximum apparent contact angle of $161.4^{\circ}$ was achieved with a contact angle hysteresis of less than $5^{\circ}$. The proposed method was shown to be capable of a maximum processing rate of $823 \mathrm{~mm}^{2} / \mathrm{min}$ and of being useful as a direct processing method.

By creating a replica mold, it might be possible to apply this novel laser processing method to conventional injection molding. Additional evaluation may be required for the hole diameter that also affects the hole depth. 
Acknowledgments This work was supported in part by the Endowed Course on Processing Based on Biomimetics, Shinshu University (financed by Ryoden Co., Japan; chair: Professor Masaki Yamaguchi) and the grant no. 20H04514 from the Japan Society for the Promotion of Science entitled "the Ultra-sensitive and rapid cancer testing technique based on fiber-type amplification” (P.I. M. Yamaguchi).

Credit Authorship Contribution Statement Hidenori Shimada: Investigation, Methodology, Writing original draft. Shunichi Kato: Investigation, Data curation. Takumi Watanabe: Data curation. Masaki Yamaguchi: Conceptualization, Investigation, Formal analysis, Writing - review \& editing, Supervision, Project administration, Funding acquisition.

\section{Compliance with Ethical Standards}

Declaration of Competing Interest The authors declare that they have no known competing financial interests or personal relationship that could have appeared to influence the work reported in this paper.

Open Access This article is licensed under a Creative Commons Attribution 4.0 International License, which permits use, sharing, adaptation, distribution and reproduction in any medium or format, as long as you give appropriate credit to the original author(s) and the source, provide a link to the Creative Commons licence, and indicate if changes were made. The images or other third party material in this article are included in the article's Creative Commons licence, unless indicated otherwise in a credit line to the material. If material is not included in the article's Creative Commons licence and your intended use is not permitted by statutory regulation or exceeds the permitted use, you will need to obtain permission directly from the copyright holder. To view a copy of this licence, visit http://creativecommons.org/licenses/by/4.0/.

\section{References}

1. Bhushan, B.: Lessons from nature for green science and technology: an overview and bioinspired superliquiphobic/philic surfaces. Philosophical Transactions of the royal society A Mathematical Phys Eng Sci. 377(2138), 20180274 (2019). https://doi.org/10.1098/rsta.2018.0274

2. Barthlott, W., Mail, M., Bhushan, B., Koch, K.: Plant surfaces: structures and functions for biomimetic innovations. Nanomicro Lett. 9(2), 23 (2017). https://doi.org/10.1007/s40820-016-0125-1

3. Martin, S., Brown, P.S., Bhushan, B.: Fabrication techniques for bioinspired, mechanically-durable, superliquiphobic surfaces for water, oil, and surfactant repellency. Adv Colloid Interf Sci. 241, 1-23 (2017). https://doi.org/10.1016/j.cis.2017.01.004

4. Bhushan, B., Jung, Y.C.: Natural and biomimetic artificial surfaces for superhydrophobicity, selfcleaning, low adhesion, and drag reduction. Prog Mater Sci. 56(1), 1-108 (2011). https://doi.org/10. 1016/j.pmatsci.2010.04.003

5. Webb, H.K., Hasan, J., Truong, V.K., Crawford, R.J., Ivanova, E.P.: Nature inspired structured surfaces for biomedical applications. Curr Med Chem. 18(22), 3367-3375 (2011). https://doi.org/10.2174/ 092986711796504673

6. Adamson, A.W., Gast, A.P.: Physical chemistry of surfaces. Wiley-Interscience, New York (1997)

7. Butt, H.-J., Roisman, I.V., Brinkmann, M., Papadopoulos, P., Vollmer, D., Semprebon, C.: Characterization of super liquid-repellent surfaces. Curr Opin Colloid Interface Sci. 19(4), 343-354 (2014). https://doi.org/10.1016/j.cocis.2014.04.009

8. Choi, H.-J., Choo, S., Shin, J.-H., Kim, K.-I., Lee, H.: Fabrication of Superhydrophobic and Oleophobic surfaces with overhang structure by reverse Nanoimprint lithography. J Phys Chem C. 117(46), 24354 24359 (2013). https://doi.org/10.1021/jp4070399

9. Lee, H., Bhushan, B.: Fabrication and characterization of hierarchical nanostructured smart adhesion surfaces. J Colloid Interface Sci. 372(1), 231-238 (2012). https://doi.org/10.1016/j.jcis.2012.01.020

10. Bhushan, B., Koch, K., Jung, Y.C.: Fabrication and characterization of the hierarchical structure for superhydrophobicity and self-cleaning. Ultramicroscopy. 109(8), 1029-1034 (2009). https://doi.org/10. 1016/j.ultramic.2009.03.030 
11. Ebert, D., Bhushan, B.: Durable Lotus-effect surfaces with hierarchical structure using micro- and nanosized hydrophobic silica particles. J Colloid Interface Sci. 368(1), 584-591 (2012). https://doi.org/ 10.1016/j.jcis.2011.09.049

12. Lee, Y.H., Choi, K.J.: Analysis of silicon via hole drilling for wafer level chip stacking by UV laser. Int J Precis Eng Manuf. 11(4), 501-507 (2010). https://doi.org/10.1007/s12541-010-0055-7

13. Ashkenasi, D., Kaszemeikat, T., Mueller, N., Dietrich, R., Eichler, H.J., Illing, G.: Laser trepanning for industrial applications. Phys Procedia. 12(B), 323-331 (2011). https://doi.org/10.1016/j.phpro.2011.03. 140

14. Kaspar, J., Luft, A., Nolte, S., Will, M., Beyer, E.: Laser helical drilling of silicon wafers with ns to fs pulses: scanning electron microscopy and transmission electron microscopy characterization of drilled through-holes. J Laser Appl. 18(2), 85-92 (2006). https://doi.org/10.2351/1.2164480

15. Gupta, S., Molian, P.: Design of laser micromachined single crystal $6 \mathrm{H}-$ SiCdiaphragms for hightemperature micro-electro-mechanical-system pressuresensors. Mater Des. 32(1), 127-132 (2011). https://doi.org/10.1016/j.matdes.2010.06.024

16. Zhu, H., Zhang, Z., Xu, K., Xu, J., Zhu, S., Wang, A., Qi, H.: Performance evaluation and comparison between direct and chemical-assisted picosecond laser micro-trepanning of single crystalline silicon. Materials (Basel). 12(1), 41 (2019). https://doi.org/10.3390/ma12010041

17. Torres-Peiró, S., González-Ausejo, J., Mendoza-Yero, O., Mínguez-Vega, G., Lan-cis, J.: Femtosecond laser micromachining with extended depth of focus by usingdiffractive lenses. Appl Surf Sci. 303, 393398 (2014). https://doi.org/10.1016/j.apsusc.2014.03.012

18. Kunz, C., Müller, F.A., Gräf, S.: Multifunctional hierarchical surface structures by femtosecond laser processing. Materials (Basel). 11(5), 789 (2018). https://doi.org/10.3390/ma11050789

19. Fan, O., Pan, R., Zhong, M.: Ultrafast laser enabling hierarchical structures for versatile Superhydrophobicity with enhanced Cassie-Baxter stability and durability. Langmuir. 35(51), 1669316711 (2019). https://doi.org/10.1021/acs.langmuir.9b02986

20. Cardoso, J.T., Aguilar-Morales, A.I., Alamri, S., Huerta-Murillo, D., Cordovilla, F., Lasagni, A.F., Ocaña, J.L.: Superhydrophobicity on hierarchical periodic surface structures fabricated via direct laser writing and direct laser interference patterning on an aluminium alloy. Opt Lasers Eng. 111, 193-200 (2018). https://doi.org/10.1016/j.optlaseng.2018.08.005

21. Lang, V., Voisiat, B., Lasagni, A.F.: High throughput direct laser interference patterning of aluminum for fabrication of super hydrophobic surfaces. Materials. 12(9), 1481 (2019). https://doi.org/10.3390/ ma12091484

22. Chichkov, B.N., Momma, C., Nolte, S., von Alvensleben, F., Tünnermann, A.: Femtosecond, picosecond and nanosecond laser ablation of solids. Appl Phys A Mater Sci Process. 63(2), 109-115 (1996). https:// doi.org/10.1007/BF01567637

23. Mirza, I., Bulgakova, N. M., Tomáštík, J. V., Michálek, Haderka, O., Fekete, L., Mocek, T.: Ultrashort pulse laser ablation of dielectrics: Thresholds, mechanisms, role of breakdown. Sci. Rep. UK. 6, 39133 (2016) https://doi.org/10.1038/srep39133

24. Wolff, S., Saxena, I.: A preliminary study on the effect of external magnetic fieldson laser-induced plasma micromachining (LIPMM). Manuf Lett. 2(2), 54-59 (2014). https://doi.org/10.1016/j.mfglet. 2014.02.003

25. Jagdheesh, R., García-Ballesteros, J.J., Ocaña, J.L.: One-step fabrication of near superhydrophobic aluminum surface by nanosecond laser ablation. Appl Surf Sci. 374, 2-11 (2016). https://doi.org/10. 1016/j.apsusc.2015.06.104

26. Hopp, B., Csete, M., Re've'sz, K., Vinko', J., Bor, Zs.: Formation of the surface structure of polyethylene-terephtalate (PET) due to ArF excimer laser ablation. Appl. Surf. Sci. 96-98, 611616. SSID. 0169-4332(95), 00563-00563 (1996)

27. Malinauskas, M., Žukauskas, A., Hasegawa, S., Hayasaki, Y., Mizeikis, V., Buividas, R., Juodkazis, S.: Ultrafast laser processing of materials: from science to industry. Light: Sci Appl. 5(8), e16133 (2016). https://doi.org/10.1038/lsa.2016.133

28. Lantada, A.D., Hengsbach, S., Bade, K.: Lotus-on-chip: computer-aided design and 3D direct laser writing of bioinspired surfaces for controlling the wettability of materials and devices. Bioinspir Biomim. 12(6), 066004 (2017)

29. Zhang, Y., Zou, G., Liu, L., Zhao, Y., Liang, Q., Wu, A., Zhou, Y.N.: Time-dependent wettability of nano-patterned surfaces fabricated by femtosecond laser with high efficiency. Appl Surf Sci. 389, 554 559 (2016). https://doi.org/10.1016/j.apsusc.2016.07.089

30. Gedvilas, M., Indrisiunas, S., Voisiat, B., Stankevicius, E., Selskis, A., Raciukaitis, G.: Nanoscale thermal diffusion during the laser interference ablation using femto-, pico-, and nanosecond pulses in silicon. Phys Chem Chem Phys. 20(17), 12166-12174 (2018). https://doi.org/10.1039/c7cp08458g 
31. Bradley, D., Sheppard, C.G.W., Suardjaja, I.M., Woolley, R.: Fundamentals of high-energy spark ignition with lasers. Combust Flame. 138(1-2), 55-77 (2004). https://doi.org/10.1016/j.combustflame. 2004.04.002

32. Kietzig, A-M., Hatzikiriakos, S. G., Englezos, P.: Patterned Superhydrophobic Metallic Surfaces. Langmuir 25(8), 4821—4827 (2009) https://doi.org/10.1021/la8037582

33. Kietzig, A.-M., Mirvakili, M.N., Kamal, S., Englezos, P., Hatzikiriakos, S.G.: Laser-patterned superhydrophobic pure metallic substrates: cassie to wenzel wetting transitions. J. Adhes. Sci. Technol. 25(20), 2789-2809 (2011). https://doi.org/10.1163/016942410X549988

34. Yang, Z., Liu, X., Tian, Y.: Insights into the wettability transition of nanosecond laser ablated surface under ambient air exposure. J Colloid Interface Sci. 533, 268-277 (2019). https://doi.org/10.1016/j.jcis. 2018.08.082

35. Byskov-Nielsen, J., Balling, P.: Laser structuring of metal surfaces: micro-mechanical interlocking. Appl Surf Sci. 255(10), 5591-5594 (2009). https://doi.org/10.1016/j.apsusc.2008.07.118

36. Ahmmeda, K.M.T., Kietzig, A.-M.: Drag reduction on laser-patterned hierarchical superhydrophobic surfaces. Soft Matter. 12(22), 4912-4922 (2016). https://doi.org/10.1039/C6SM00436A

37. Wu, B., Zhou, M., Li, J., Ye, X., Li, G., Cai, L.: Superhydrophobic surfaces fabricated by microstructuring of stainless steel using a femtosecond laser. Appl Surf Sci. 256(1), 61-66 (2009). https://doi.org/10.1016/j.apsusc.2009.07.061

38. Elsied, A.M., Dieffenbach, P.C., Diwakar, P.K., Hassanein, A.: Nanosecond laser-metal ablation at different ambient conditions. Spectrochim Acta B. 143, 26-31 (2018). https://doi.org/10.1016/j.sab.2018. 02.012

39. Nosonovsky, M., Bhushan, B.: Multiscale friction mechanisms and hierarchical surfaces in nano- and bio-tribology. Mater. Sci. Eng. R Rep. 58(3-5), 162-193 (2007) https://doi.org/10.1016/j.mser.2007. 09.001

40. Nosonovsky, M., Bhushan, B.: Patterned nonadhesive surfaces: Superhydrophobicity and wetting regime transitions. Langmuir. 24(4), 1525-1533 (2008). https://doi.org/10.1021/la702239w

41. Cai, Y., Chang, W., Luo, X., Sousa, A.M.L., Lau, K.H.A., Qin, Y.: Superhydrophobic structures on 316L stainless steel surfaces machined by nanosecond pulsed laser. Precis Eng. 52, 266-275 (2018). https://doi.org/10.1016/j.precisioneng.2018.01.004

42. Yang, Z., Tian, Y., Zhao, Y., Yang, C.: Study on the fabrication of super-hydrophobic surface on inconel alloy via nanosecond laser ablation. Materials (Basel) 12(2), 278 (2019) https://doi.org/10.3390/ ma12020278

Publisher's Note Springer Nature remains neutral with regard to jurisdictional claims in published maps and institutional affiliations. 